\title{
Characterization and evaluation for wound healing of chitosan extracted from the exoskeleton of freshwater crab Potamonautes niloticus
}

\author{
Mohamed Abdelnaser Amer ${ }^{*}$, Enas M.H. Attia ${ }^{2}$ \\ 'Zoology Department, Faculty of Science, Al-Azhar University, Cairo, Egypt. \\ ${ }^{2}$ Physics Department, Faculty of Science (Girls), Al-Azhar University, Cairo, Egypt.
}

\begin{tabular}{l}
\hline ARTICLE INFO \\
\hline Received on: $28 / 11 / 2019$ \\
Accepted on: $14 / 02 / 2020$ \\
Available online: $06 / 05 / 2020$
\end{tabular}

\section{Key words:}

Re-epithelization, inflammatory phase, chitin, crustacean shells.

\begin{abstract}
The freshwater crab Potamonautes niloticus (Potamonautidae: Decapoda: Crustacea) is common in River Nile and its tributaries but has no commercial value as edible crab for human beings. Therefore, the present study aims to evaluate the role of chitosan extracted from its exoskeleton for wound healing process as a medical application. The structure of chitosan has been physically investigated by using fourier transformer infrared spectroscopy to reveal the vibrational frequencies of different structural functional groups, such as primary amine groups, hydroxyl groups and amide groups. The efficiency of the extracted chitosan was assessed by morphological and histological examination of wound healing in albino rats. Sections of isolated wounds were stained with hematoxylin and eosin to evaluate the histological changes during the wound healing process. Chitosan was yielded $30.64 \%$ from the crab shells and the results of wound healing assessments showed that the chitosan treated group (Ch 1\%) was more efficient and faster

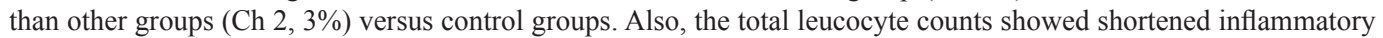
phase in chitosan-treated groups. The present results showed the efficiency of extracted chitosan in wound healing process and can be used in medical applications.
\end{abstract}

\section{INTRODUCTION}

The two Afrotropical species of freshwater crabs, Potamonautes berardi (Audouin, 1826) and Potamonautes niloticus(H.MilneEdwards, 1837) belong toFamily Potamonautidae are well known in the River Nile and its tributaries. These species are in close to the Palaearctic species, Potamon potamios Olivier, 1804 (Family: Potamidae), an eastern Mediterranean taxon whose range extends into the Sinai Peninsula (Brandis et al., 2000). Potamonautes niloticus and P. berardi are common and widespread throughout the River Nile basin from the delta in Egypt to Lake Victoria and its tributaries in equatorial Africa. The most common species in the northern limit is $P$. niloticus which has a very wide distribution; from Egypt, Sudan, Ethiopia, Uganda, Kenya and Rwanda. Fishermen have the crabs caught in their fishing nets

\section{"Corresponding Author}

Mohamed Abdelnaser Amer, Zoology Department, Faculty of Science, Al-Azhar University, Cairo,Egypt.E-mail:naseramer@azhar.edu.eg while targeting mainly crayfish and then they discard the undesired caught crabs because these populations of crabs are to the best of my knowledge not yet commercially evaluated.

In fact, freshwater crabs were considered as an important source of chitin as the other crustaceans (Bolat et al., 2010). Chitosan is traditionally obtained from crustacean shells (crabs, shrimps and crayfish) with natural cationic polysaccharide composed of 2-acetamido-2deoxy-b-D-glucopyranose and 2-amino-2-deoxy-bD-glucopyranose (De Oliviera et al., 2014).

Depending on the species and season, crustacean shells or exoskeletons are composed of $30 \%-40 \%$ protein, $30 \%-50 \%$ calcium carbonate and $20 \%-30 \%$ chitin. A rate of $1010-1011$ tons per year is the amount of chitin produced from crustaceans, insect exoskeletons and cell wall of fungi, which are unusable wastes (Gopalan and Dufresne, 2003). It was determined that the shrimp (Pandalus borealis) contains about 17\%-32.2\% chitin (Shahidi and Synowiecki, 1991) while the chitin isolated from the crab, Chionoecetes opilio, contains 26.6\% chitin (Hong and Mun, 1995).

Because of the outstanding biological features of chitosan, including its biodegradability, biocompatibility and 
nontoxicity; it is used in the food, agriculture, textile, water treatment, cosmetics and other industries with or without other natural polymers (alginates, starch and gelatin) additives (Kammoun et al., 2013). Since chitosan was an applicable compound to use in medical and commercial industries, it considers as biodegradable, non-toxic, anti-fungal and antibacterial biomaterial compound (Ahmed and Sastry, 2011; Baldrick, 2010; Daniela and Camelia, 2008; Gokarneshan, 2017; Shi et al., 2009).

The effect of chitin and its derivatives on fibroblasts and production of cytokines were reported by Mori et al. (1997); while Usami et al. (1994a, 1994b) found that chitin and chitosan have enhanced the activation of bovine and canine polymorph nuclear cells. Moreover, chitosan is of biomedical importance, for example, wound healing processes (Shakeel and Ikram, 2016). Moreover, Patrulea et al. (2015) concluded from their review that the chitosan is an efficient compound in wound healing application; also, it is a good accelerator material for wound healing (Yilmaz, 2004).

Wound repair or healing in which tissue repair itself after injury (Cordoso et al., 2010; Nilani et al., 2011) one of the applications that can be used to test the effect of chitosan on various tissues. The healing process begins with blood clotting and can be generally classified to: inflammation, granular tissue formation, re-epithelialization, matrix production and remodeling (Janis et al., 2010). While Barbul and Regan (1993) classified this process to three phases comprised: inflammation, proliferation and maturation. Archana et al. (2013) stated that the wound healing is a series of complex steps starting with inflammation followed by cell migration, angiogenesis provisional matrix synthesis, collagen deposition and re-epithelization.

Generally, there are two models to test wound healing; incisional and excisional (Dorsett-Martin, 2004), but excisional model is more appropriate to determine histological and morphological changes during the healing process. Azuma et al. (2015) studied the excisional model on rat's wounds and found that wounds healed in group treated with chitosan are $99 \%$ higher than control groups $82 \%$.

Hence, the present study aims to test an applicable material (chitosan) extracted from the non-economic freshwater crab $P$. niloticus on wound healing process caused by circular excision of skin in normal healthy rats.

\section{MATERIALS AND METHODS}

\section{Extraction of chitosan}

Forty six individuals of freshwater crab P. niloticus were collected from River Nile Tributaries, then transported to the laboratory, Faculty of Science, Al-Azhar University during August/2018. Crab exoskeletons were separated after dissecting all individuals in pre-iced jars. All crab exoskeleton wastes were washed with tap water then boiled and dried in room temperature for 24 hours. The extraction of chitosan was carried out according to Hossain and Iqbal (2014) with modification in demineralization step, using glacial acetic acid instead of hydrochloric acid. 1) Demineralization, by glacial acetic acid $5 \%$ for 1 hour at room temp. 2) Deproteinization by $\mathrm{NaOH} 4 \%$ for 2 hours at $65 \mathrm{C}^{\circ}$ and 3 ) Deacetylation by $\mathrm{NaOH} 50 \%$ for 20 hours at $65 \mathrm{C}^{\circ}$.

\section{Physical characterization of chitosan}

Chitosan was characterized by using fourier transformer infrared spectroscopy (FTIR spectra) in a range of 400 to $3,600 \mathrm{~cm}^{-1}$.

\section{Wound healing experiment}

A total of 25 male albino rats were obtained from Vacsera Farm, Helwan branch by delivery mediator and transported to the Animal House, Faculty of Science, to perform this experiment during October/2018. The animals were acclimated for 2 weeks before the experiment, all cages containing the experimental animals were cleaned, sterilized and changed the bedding (sawdust) every 2 days. Animals were separated into five groups (five in each) comprised: (1) -ve CG (negative control group without any treatment), (2) +ve CG (positive control group treated with commercial ointment of $25 \% \mathrm{w} / \mathrm{w} \beta$-sitosterol), (3) Ch $1 \%$ (chitosan film 1\% treated group), (4) Ch 2\% (chitosan film 2\% treated group) and (5) Ch 3\% (chitosan film 3\% treated group). Chitosan concentrations were determined based on studies carried out by Bujang et al. (2013) and No et al. (2002). Diethyl ether was used as anesthetic before wound injury. A small sterilized puncher used for performing two round wounds, $\sim 1 \mathrm{~cm}$ in diameter, on the back of each rat (Fig. 1).

\section{Morphological evaluation}

Wound closure was measured by Vernier Caliper at each: 1, 4, 8, 12 and 16 day's intervals after surgery (Fig. 1).

\section{Histological evaluation}

It was performed by excision the rounded wounds of sacrificed rats (sacrificed by diethyl ether inhalation before excision). Then, the excised wounds preserved in formalin $10 \%$ and followed the basic histological preparation (fixation, dehydration, embedding and cutting sections). Sections were stained with hematoxylin-eosin to assess the phases of wound healing.

Total leucocytes count was estimated by automated Complete Blood Count veterinary Counter.

\section{Morphometric measurements}

The stained sections were examined under light microscope (Leica DM -LB2) provided with a digital camera (Sanyo vcc-6580PE) for photography. For each section, prepared samples from each rat was subjected to the following measurements: i) Thickness of epidermal layer $(\mu \mathrm{m})$, ii) Thickness

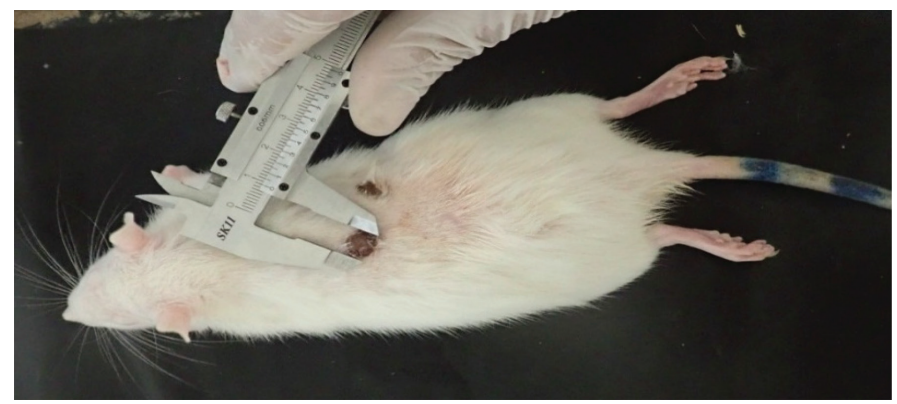

Figure 1. Measuring of wound closure using Vernier Caliper during healing process after treatment. 
of dermal layer $(\mu \mathrm{m})$, iii) Number of hair follicles and Sebaceous glands /field.

\section{Statistical analyses}

Statistical analyses were carried out using Microsoft Office 365 Excel program, ANOVA (Single factor).

\section{RESULTS AND DISCUSSION}

\section{Chitosan yield}

A total of $57.6 \mathrm{~g}$ chitosan was extracted from 46 individual's exoskeleton of the freshwater crab P. niloticus. This amount represents $30.64 \%$ out of $188 \mathrm{~g}$ of dried crab exoskeleton after final step of deacetylation, which in the range of those reported in some studied crustaceans (Cho et al., 1999) and being higher than that determined in crab C. opilio and shrimp P. borealis (Hong and Mun, 1995; Shahidi and Synowiecki, 1991).

\section{Physical characterization}

Fig. 2 represents FTIR transmittance spectra of chitosan powder isolated and prepared from $P$. niloticus. Stretching vibrations of primary and secondary hydroxyl groups are represented by the

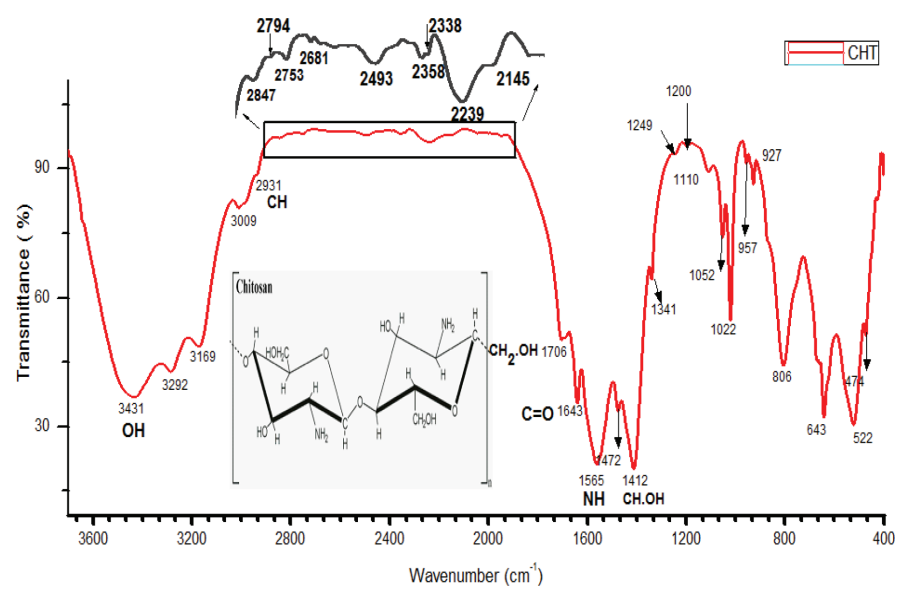

Figure 2. FTIR transmittance spectra of chitosan powder isolated from $P$. niloticus (the graph range between 2,850 and 2,000 has been enlarged due to lower intensity of peak existence). principal spectral broad band between $3,431 \mathrm{~cm}^{-1}$ to $3,009 \mathrm{~cm}^{-1}$. The stretching vibrations of $\mathrm{C}=\mathrm{O}$ and $\mathrm{C}-\mathrm{O}$ of primary alcohols were located at 1,413 and $1,052 \mathrm{~cm}^{-1}$, respectively. The band at 1,338 $\mathrm{cm}^{-1}$ was assigned to amide III and the spectral band at $1,243 \mathrm{~cm}^{-1}$ was attributed to complex vibration of NHCO group. The C-O-C glycoside linkage vibration was observed at $1,198 \mathrm{~cm}^{-1}$. The bands at 1,052 and 1,022 were ascribed to stretching of $\mathrm{C}-\mathrm{O}$ bonds of the primary alcohols. An angular deformation of $\mathrm{C}-\mathrm{H}$ bonds of methyl group were observed at the band of $1,475 \mathrm{~cm}^{-1}$. The existence of a band at $3,282 \mathrm{~cm}^{-1}$ is attributed to the hydrogen bonded $\mathrm{NH}$ groups of the secondary amide. The ring vibrations in C-C were represented by several bands at 677,806 and $957 \mathrm{~cm}^{-1}$. The presence of spectral peak at 1,563 corresponds to the protonation of $\mathrm{NH} 3+$ groups. The bands at 2,931, 2,847, $957 \mathrm{~cm}^{-1}$ were ascribed to $\mathrm{C}-\mathrm{H}$ bonds stretching. The stretching vibrations in amide II group was located at $1,643 \mathrm{~cm}^{-1}$. All bands that are observed in FTIR spectrum are detailed in Table 1.

Noteworthy, the band of $1,643 \mathrm{~cm}^{-1}$, that is assigned to $\mathrm{C}=\mathrm{O}$ of the primary amide group of the extracted chitosan shows similarity with the reported peak by Norhidayah et al. (2017) for commercial chitosan. The appearance of bands at 1,022 and 1,052 $\mathrm{cm}^{-1}$ is contributed by the stretching of $\mathrm{C}=\mathrm{O}$ bonds of the primary alcohols. However, few bands of the chitosan prepared in the present study are absent in the commercial chitosan presented by Norhidayah et al. (2017).

\section{Morphological and histological evaluation of wound healing}

The uses of morphological and histological examination of healing rat wounds using the present extracted chitosan as a treatment are more appropriate methods to assess the wound healing factors as previously proposed (Gal et al., 2008; Vidinsky et al., 2006).

To evaluate the effectiveness of chitosan extracted from the crab exoskeleton waste as a wound dressing material, an in vivo macroscopic wound closure study was performed. During this study, the macroscopic observation of wound closure in control groups, including $(-\mathrm{ve})$ untreated and $(+\mathrm{ve})$ treated with commercial wound healing material versus treated groups with chitosan film $(1 \%, 2 \%$ and $3 \%)$ was examined at $4,8,12$ and 16 days after surgery (Fig. $3 a$ and $b$ ).

In -ve control group, the closure of wound not completely healed at the end of the experiment at Day 16, but the +ve control

Table 1. Characterization of chitosan (present study) using IR in comparison with commercial chitosan.

\begin{tabular}{ccll}
\hline \multicolumn{2}{c}{ Frequency wave number $\left(\mathbf{c m}^{-1}\right)$} & \multirow{2}{*}{ Assignment } \\
\cline { 1 - 3 } Chitosan present study & $\begin{array}{c}\text { Commercial chitosan } \\
\text { (Norhidayah et al., 2017) }\end{array}$ & \\
\cline { 1 - 3 } $3,431-3,009$ & - & Primary and secondary Hydroxyl groups $(\mathrm{O}-\mathrm{H})$ groups stretching \\
3,282 & 2,921 & Hydrogen bonded NH groups of Amide II \\
$2,931 \& 2,847$ & - & C-H bonds stretching \\
1,563 & $\mathbf{1 , 6 4 3}$ & Protonated $\mathrm{NH}_{3}^{+}$groups \\
1,643 & - & C=O stretching of the amide II group \\
1,475 & 1,430 & Angular deformations of C-H group of methyl group \\
1,413 & - & CH2 bending and C=O stretching \\
1,338 & 1,070 & Amide III [2013 reference no 29 says that its peak is at 1,320] \\
$1,052 \& 1,022$ & 1,262 & Stretching of C-O bonds of the primary alcohols. \\
1,243 & 1,154 & Complex vibration of NHCO group \\
$677-806-957$ & 699 & C-O-C glycoside linkage \\
& & Ring vibrations C-C \\
\hline
\end{tabular}


a)

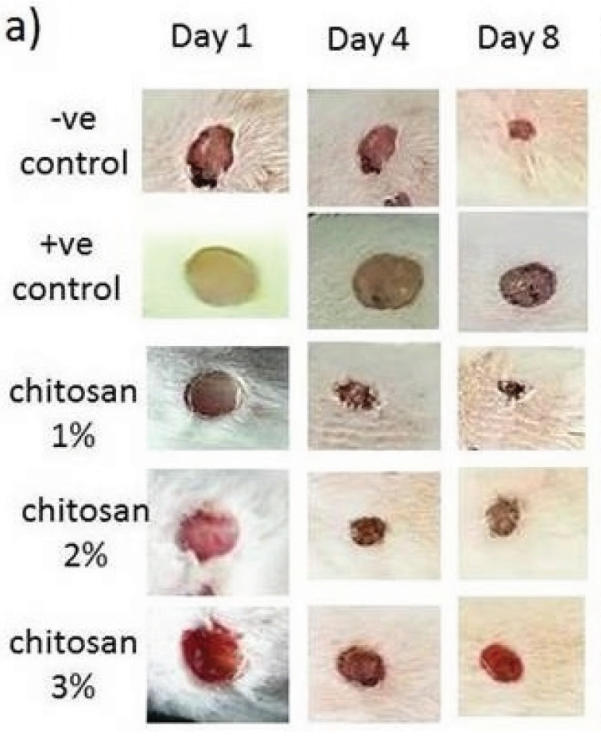

Day 12 Day 16

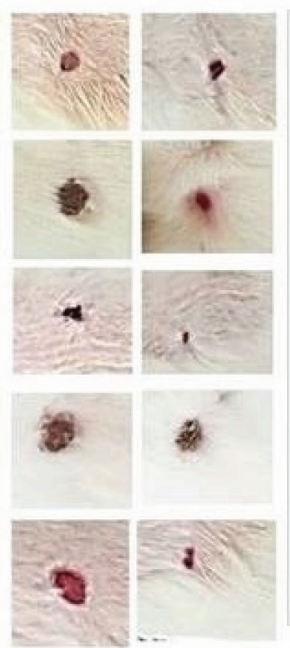

b)

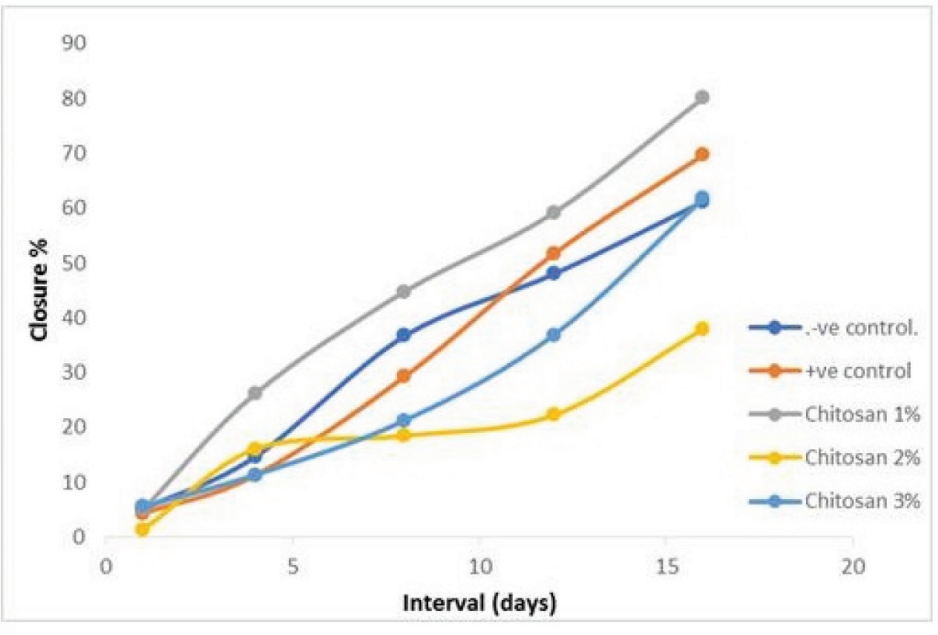

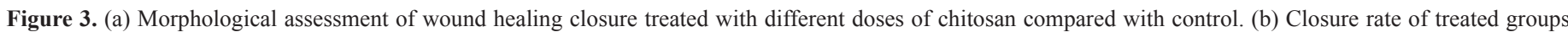
versus control groups.

showed more healing performance at Days 12 and 16. Moreover, scar formation weakly observed in both previous groups. On the other hand, the Ch $1 \%$ treated group showed the best performance of wound closure compared with control groups started at Day 4, in addition to the formation of scar at Days 4, 8, 12, with closure rate, $44.7 \%, 59.1 \%$ and $80 \%$, respectively and almost completed healing at Day 16, this was less than reported complete healing range period of 3 weeks (Dreifke et al., 2015). However, the macroscopic observation for treated groups, Ch $2 \%$ and $3 \%$ showed less effectiveness of wound closure during the period of the experiment despite of the formation of the scar, with lower closure rate. The present results showed that the most effective treatment on wound closure rate was chitosan treated group (1\%) followed by positive control group (commercial product), indicating that the present prepared chitosan is more effective at concentration $1 \%$ comparable with commercial products and other concentrations and the statistical analyses confirmed the difference in closure rate, it was significant $(p<0.05)$ between groups.

\section{Histological evaluation of wound healing}

Microscopic examinations for control and treated groups sectioned samples of rat wounds stained with $H \& E$ at 4 , 8 and 16 days intervals were carried out to evaluate the recovery of skin tissue (Fig. 4). After Day 4, the H\&E stained sections showed no scar formation in -ve and +ve control groups but was clearly observed in Ch $1 \%$ treatment group and hardly indicated in the treatment groups of $\mathrm{Ch} 2 \%$ and $3 \%$. On the other hand, re-epithelization was showed only in +ve CG and $\mathrm{Ch} 1 \%$ treatment groups. These results are in well agreement with Azuma et al. (2015) on the assessment of chitosan derivatives after 4 and 8 days and the re-epithelization was completed after 16 days indicating that chitosan prompts good re-epithelization with no scar formation which agree with No et al. (2002).
Moreover, sections of the treated groups were highly filled with newly formed blood vessels. In -ve and +ve control groups, new blood vessel formation delayed and observed at Day 8 , while the granulation in the epidermis recorded first in the treatment groups at Day 8 .

At Day 16, sebaceous glands observed in all groups except -ve CG, while hair follicles observed only in treatment groups; remarkably in $\mathrm{Ch} 1 \%$ and $2 \%$ groups. On the other hand, the thickness of the epidermis in Ch $1 \%$ \& $2 \%$ groups were higher than $\mathrm{Ch} \mathrm{3 \%}$, but the complete wound healing observed only in $\mathrm{Ch}$ $1 \%$ and $2 \%$ treatment groups at the end of the experiment.

By contrast, regeneration of tissues in wounds of treated groups were achieved at Days 4 and 8 but, delayed in control groups till Day 8. Moreover, the thickness of epidermis was increased significantly in Ch $1 \%$ and $2 \%$ treated groups at Days 4 and 8 comparable to control groups.

\section{Total leucocyte count}

The total averages of leucocyte count in the treatment groups versus control groups after $4,8,12,16$ days are shown in Table 2. Despite of there was no significance difference $(p>0.05)$ in the total leucocytes count between groups; the present results exhibit remarkable gradual decreasing in leucocyte number with an increasing period of treatment with chitosan. The maximum total leucocyte count estimated at Day 4 for all treated groups. The highest averaged values were $8.3,6.1$ and 11.6 for $1 \%, 2 \%$ and $3 \%$ chitosan treated groups, respectively. However, these values had decreased gradually at Days 8, 12 and reached the lowest values at Day 16 in the treated groups. On the other hand, control groups showed variable pattern at Days 4-16 with relatively lower values (Table 2). This indicates that chitosan promotes the inflammatory phase faster than control groups, as mentioned by both of Muzzarelli et al. (1990) and Seyfarth et al. (2008). 


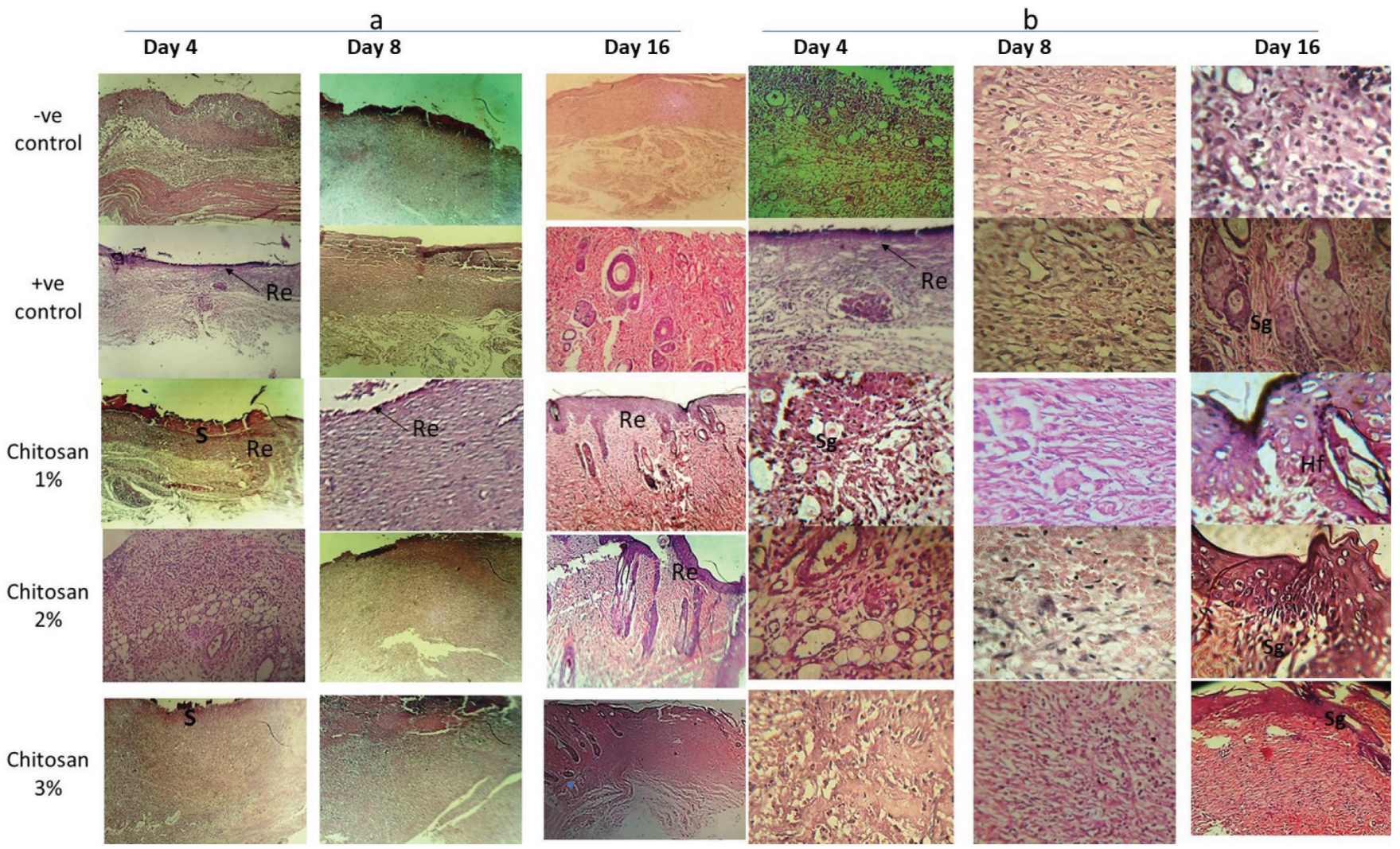

Figure 4. Histological examination of rat skin wounds H\&E staining for control (-ve \& +ve) versus treated groups (ch. 1\%, 2\% and 3\%) after 4, 8 and 16 days of treatment; re-epithelization indicated by arrows, $\mathrm{S}$ (scar formation), Sg; sebaceous glands and Hf; hair follicle. (a) magnification 50×. (b) magnification 100×.

Table 2. Showing average \pm standard deviation total count of leucocytes in the chitosan treated groups versus control groups during this study.

\begin{tabular}{cccccc} 
Groups & Ch 2\% & Ch 3\% & -ve CG & +ve CG \\
\hline $\begin{array}{c}\text { Period } \\
\text { (post-surgery) }\end{array}$ & & & & \\
\hline Day 4 & $8.3 \pm 0.27$ & $6.1 \pm 0.34$ & $11.6 \pm 0.48$ & $3.9 \pm .46$ & $4.2 \pm 0.12$ \\
Day 8 & $5.4 \pm 0.43$ & $4.7 \pm 0.39$ & $7.7 \pm 0.27$ & $2.8 \pm 0.34$ & $7.3 \pm 0.32$ \\
Day 12 & $4.3 \pm 0.15$ & $4.1 \pm 0.72$ & $5.3 \pm 0.42$ & $3.7 \pm 0.52$ & $4.7 \pm 0.28$ \\
Day 16 & $3.5 \pm 0.22$ & $4.1 \pm 0.23$ & $3.1 \pm 0.47$ & $2.8 \pm 0.31$ & $3.9 \pm 0.37$ \\
\hline
\end{tabular}

\section{CONCLUSION}

The present study provides a commercial importance of freshwater crab P. niloticus which considers as a good source of chitosan extracted from its exoskeleton that evaluated in present study for wound healing application. The present results ensure the efficiency of chitosan in accelerating the wound healing process with less inflammatory phase.

\section{ACKNOWLEDGMENTS}

The first author is very grateful to Professors Omer Elmenshawy and Awaad M. El-Sayed, Faculty of Science, Al-Azhar University in reviewing this manuscript. Also, the author would like to thank Dr. Saad Moghannem and Dr. Ahmed Ali Radwan for their help in preparation of chitosan films, Faculty of Science, Al-Azhar University.

\section{CONFLICT OF INTERESTS}

The authors declare that there are no competing interests.

\section{ETHICS APPROVAL AND CONSENT TO PARTICIPATE}

The present studied animals were treated according to "Ethical guidelines for the care and use of animals in education \& scientific Research" and approved through the Ethical Committee of Faculty of Pharmacy, Ain Shams University. (Reference Number: ENREC-ASU.2019-99)

\section{FUNDING}

No funding was obtained for this study.

\section{AUTHORS' CONTRIBUTIONS}

M.A. collected the crab specimens and extracted the chitosan material; the wound healing experiment was investigated 
also by M.A. E.A. involved in the physical characterization of the chitosan material. M.A. and E.A. contributed in the preparing and editing the whole manuscript. All authors have read and approved the manuscript.

\section{REFERENCES}

Ahmed NMI, Sastry TP. Wound dressing application of chitosan based bioactive compounds. Inter J Phar Life Sci, 2011; 2(8):991-6.

Archana D, Dutta J, Dutta P. Evaluation of chitosan nano dressing for wound healing: characterization, in vitro and in vivo studies. Inter J Biol Macromolec, 2013; 57:193-203.

Azuma K, Izumi R, Osaki T, Ifuku S, Morimoto M, Saimoto H, Minami S, Okamoto Y. Chitin, chitosan, and its derivatives for wound healing: old and new materials. J Funl Biomat, 2015; 6(1):104-42. doi: 10.3390/jfb6010104.

Baldrick P. The safety of chitosan as a pharmaceutical excipient. Regul Toxicol Pharmacol, 2010; 56:290-9.

Barbul A, Regan MC. Biology of wound healing. In: Fisher JA (ed). Surgical basic science. Mosby-Yearbook, St. Louis, pp 68-88, 1993.

Bolat Y, Bilgin Ş, Günlü A, Izci L, Koca SB, Çetinkaya S, Koca HU. Chitin-Chitosan yield of freshwater crab (Potamon potamios, Olivier 1804) shell. Pak Vet J, 2010; 30(4):227-31.

Brandis D, Storch V, Turkey M. Taxonomic and zoogeography of the freshwater crabs of Europe, North Africa and the Middle East (Crustacea, Decapoda, Potamidae). Senckenberg. Biologica, 2000; 80:5-56.

Bujang A, Nur 'Adila S, Suyatma NE. Physical properties of chitosan films as affected by concentration of lactic acid and glycerol. In fourth International Conference on Biology, Environment and Chemistry IACSIT Press, Singapore, 2013; 58. doi: 10.7763/IPCBEE. 2013. V58. 6

Cho YW, Cho YN, Chung SH, Yoo G, Ko SW. Water-soluble chitin as a wound healing accelerator. Biomaterials, 1999; 20:2139-45. doi: 10.1016/S0142-9612(99)00116-7.

Cordoso CA, Favoreto S, Oliveira LL, Vancim JO, Barban GB, Ferraz DB, Silvia JS. Oleic acid modulation of the immune response in wound healing a new approach for skin repair. J Immunol, 2010; 216(3):409-15.

Daniela E, Camelia EO. Functionalized Chitosan and its use in pharmaceutical, biomedical and biotechnological research. Chem Engg Comm, 2008; 195:1269-91.

De Oliviera CE, Magnani M, Sales CV, Potes ALS, CamposTakaki GM, Stamford TCM, Souza EL. Effects of chitosan from Cunninghamella elegans on virulence of post harvest pathogenic fungi in table grapes (vitis Labrusca 1.) Int J Food Microbiol, 2014; 171:54-61. doi: 10.10161j.ijfoodmicro.2013.11.006.

Dorsett-Martin WA. Rat models of skin wound healing: a review. Wound Rep Reg, 2004; 12:91-599.

Dreifke MB, Jayasuriya AA, Jayasuriya AC. Current wound healing procedures and potential care. Mater Sci Eng, 2015; C(48):651-62.

Gal P, Kilik R, Mokry M, Vidinsky B, Vasilenko T, Mozes S, Bobrov N, Tomori Z, Bober J, Lenhardt L. Simple method of open skin wound healing model in corticosteroid-treated and diabetic rats: standardization of semi-quantitative and quantitative histological assessments. Veter Medic, 2008; 53(12):652-9.

Gokarneshan N. Review article- role of chitosan in wound healing - a review of the recent advances. Glob J Addic Rehab Med, 2017 4(3):555-636. doi: 002 10.19080/GJARM.2017.04.555637.

Gopalan NK, Dufresne A. Crab shells chitin whiskers reinforced natural rubber nanocomposites. Processing and swelling behavior. Biomacromolecules, 2003; 4(3):657-65.

Hong KN, Mun YL. Isolation of chitin from crab shell waste. J Korean Soc Food Nutr, 1995; 24:105-13.
Hossain MS, Iqbal A. Production and characterization of chitosan from shrimp waste. J Bangladesh Agril Univ, 2014; 12(1):153-60.

Janis JE, Kwon RK, Lalonde DH. A practical guide to wound healing. Plast Reconstr Surg, 2010; 125:230-44.

Kammoun M, Haddar M, Kallel TK, Dammak M, Sayari A. Biological properties and biodegradation studies of chitosan biofilms plasticized with PEG and glycerol. Int J Biol Macromol, 2013; 62:433-8. doi: 10.1016/j.ijbiomac.2013.09.025.

Mori T, Okumura M, Matsuura M, Ueno K, Tokura S, Okamoto Y, Minami S, Fujinaga T. Effects of chitin and its derivatives on the proliferation and cytokine production of fibroblasts in vitro. Biomaterials, 1997; 18:947-51. doi: 10.1016/S0142-9612(97)00017-3.

Muzzarelli R, Tarsi R, Filippini O, Giovanetti E, Biagini G, Varaldo PE. Antimicrobial properties of $N$-carboxybutyl chitosan. Anti Agents Chemother, 1990; 10:2019-23. doi: 10.1128/AAC.34.10.2019.

Nilani P, Pranavi A, Duraisamy B, Damodaran P, Subhashini V, Elango K. Formulation and evaluation of wound healing dermal patch. Afr J Pharm Pharmacol, 2011; 5(9):1252-7.

No HK, Park NY, Lee SH, Meyers SP. Antibacterial activity of chitosans and chitosan oligomers with different molecular weights. Int J Food Microbiol, 2002; 74:65-72. doi: 10.1016/S0168-1605(01)00717-6.

Norhidayah MA, Faridah M, Azrilawani A, Alyza AA. Chitin and chitosan extraction from Portunus pelagicus. Malaysian J Analyt Sci, 2017; 21(4):770-7. doi.: 10.17576/mjas-2017-2104-02

Patrulea V, Ostafe V, Borchard G, Jordan O. Chitosan as a starting material for wound healing applications. Eur J Pharm Biopharm, $2015 ; 97: 417-26$

Seyfarth F, Schliemann S, Elsner P, Hipler UC. Antifungal effect of high- and low-molecular-weight chitosan hydrochloride, carboxymethyl chitosan, chitosan oligosaccharide and $N$-acetyl-D-glucosamine against Candida albicans, Candida krusei and Candida glabrata. Int J Pharmaceut, 2008; 353:139-48.

Shahidi F, Synowiecki J. Isolation and characterization of nutrients and value-added products from snow crab (Chinoecetes opilio) and shrimp (Pandalus borealis) processing discards. J Agric Food Chem, 1991; 39:1527-32.

Shakeel A, Ikram S. Chitosan based scaffolds and their applications in wound healing. Achievem Life Sci, 2016; 10:27.

Shi C, Zhu Y, Ran X, Wang M, Su Y, Cheng T. Therapeutic potential of Chitosan and its derivatives in regenerative medicine. J Surg Res, 2009; 133:185-92.

Usami Y, Okamoto Y, Minami S, Matsuhashi A, Kumazawa NH, Tanioka S, Shigemasa Y. Chitin and chitosan induce migration of bovine polymorphonuclear cells. J Vet Med Sci, 1994a; 56:761-2. doi: 10.1292/ jvms.56.761.

Usami Y, Okamoto Y, Minami S, Matsuhashi A, Kumazawa $\mathrm{NH}$, Tanioka S. Shigemasa Y. Migration of canine neutrophils to chitin and chitosan. J Vet Med Sci, 1994b; 56:1215-6. doi: 10.1292/jvms.56.1215.

Vidinsky B, Gal P, Toporcer T, Longauer F, Lenhardt L, Bobrov N, Sabo J. Histological study of the first seven days of skin wound healing in rats. Acta Vet Brno, 2006; 75:197-202.

Yilmaz E. Chitosan: a versatile biomaterial, Adv Exp Med Biol, 2004; 553:59-68.

How to cite this article:

Amer MA, Attia E M.H. Characterization and evaluation for wound healing of chitosan extracted from the exoskeleton of freshwater crab Potamonautes niloticus. J Appl Pharm Sci, 2020; 10(05):043-048. 